\title{
Preparation of Samarium Oxide Nanoparticles Decorated Functionalized Multiwall Carbon Nanotubes Modified Electrode for the Electrochemical Determination of Catechol
}

\author{
Bhuvanenthiran Mutharani ${ }^{1}$, Subramanian Sakthinathan ${ }^{2}$, Shen-Ming Chen ${ }^{1,}$ *, Tse-Wei Chen ${ }^{1, *}$, \\ Te-Wei Chiu $^{2}$ \\ ${ }^{1}$ Electroanalysis and Bioelectrochemistry Lab, Department of Chemical Engineering and \\ Biotechnology, National Taipei University of Technology, No.1, Section 3, Chung-Hsiao East Road, \\ Taipei 106, Taiwan (R.O.C). \\ ${ }^{2}$ Department of Materials and Mineral Resources Engineering, National Taipei University of \\ Technology, No.1, Section 3, Chung-Hsiao East Road, Taipei 106, Taiwan (R.O.C). \\ *E-mail: smchen78@ms15.hinet.net, tewei@ntut.edu.tw
}

doi: $10.20964 / 2018.07 .20$

Received: 23 February 2018 / Accepted: 18 April 2018 / Published: 5 June 2018

Herein, we describe the innovative and simple voltammetric method based on the samarium oxide $\left(\mathrm{Sm}_{2} \mathrm{O}_{3}\right)$ decorated functionalized multiwall carbon nanotubes $\left(\mathrm{Sm}_{2} \mathrm{O}_{3} / \mathrm{f}-\mathrm{MWCNTs}\right)$ using as an electrode material for the detection of catechol (CC). The as-prepared $\mathrm{Sm}_{2} \mathrm{O}_{3} / \mathrm{f}-\mathrm{MWCNTs}$ composite was confirmed by using scanning electron microscopy (SEM), energy dispersive X-ray spectroscopy (EDX) and fourier-transform infrared spectroscopy (FT-IR). The electrochemical properties of the $\mathrm{Sm}_{2} \mathrm{O}_{3} / \mathrm{f}-\mathrm{MWCNTs}$ were investigated by electrochemical impedance spectroscopy (EIS), cyclic voltammetry $(\mathrm{CV})$ and differential pulse voltammetry (DPV). The as-proposed $\mathrm{Sm}_{2} \mathrm{O}_{3} / \mathrm{f}-\mathrm{MWCNTs}$ modified GCE exhibited an excellent electrocatalytic activity towards oxidation of CC. The electrochemical studies of DPV displays wide linear response range, lower detection limit and well sensitivity of $0.1-1249 \mu \mathrm{M}, 0.03 \mu \mathrm{M}$ and $0.213 \mu \mathrm{A}_{\mu} \mathrm{M}^{-1} \mathrm{~cm}^{-2}$, respectively. The as-prepared electrochemical sensor had good stability, repeatability and reproducibility for the determination of CC. Besides, the prepared electrode material modified GCE was successfully applied to the real sample analysis in various water samples and the obtained recovery from 94.5 to $99 \%$ is confirm that the $\mathrm{Sm}_{2} \mathrm{O}_{3} / \mathrm{f}-\mathrm{MWCNTs} / \mathrm{GCE}$ had better practical reliability to the determination of CC.

Keywords: Multiwall carbon nanotubes, Electrochemical sensor, Catechol, Differential pulse voltammetry, Low detection limit.

FULL TEXT 
(C) 2018 The Authors. Published by ESG (www.electrochemsci.org). This article is an open access article distributed under the terms and conditions of the Creative Commons Attribution license (http://creativecommons.org/licenses/by/4.0/). 